\title{
Brachydactylous dwarfism, Mseleni type
}

INSERM

\section{Source}

INSERM. (1999). Orphanet: an online rare disease and orphan drug data base.

Brachydactylous dwarfism, Mseleni type. ORPHA:2619

Mseleni joint disease (MJD) is a rare and crippling chondrodysplasia, reported mainly in the Maputaland region in northern Kwazulu Natal, South Africa, characterized by a bilateral and uniform arthropathy of the joints that primarily and most severely affects the hip but that can also affect many other joints (i.e. knees, ankles, wrists, shoulders, elbows), and that manifests with pain and stiffness that progressively limits joint movement, eventually compromising a patient's ability to walk. Severe short staure and brachydactyly have been reported in a few patients with MJD. 